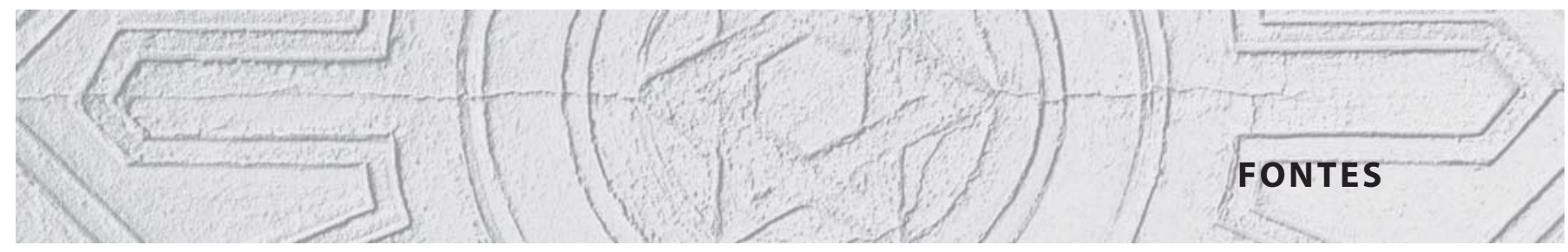

\title{
Território e saúde: o estudo de Antônio Pimentel sobre o Planalto Central ${ }^{*}$
}

\author{
Territory and health: Antônio Pimentel's study \\ on the Central Plateau
}

Moema de Rezende Vergara

Pesquisadora Adjunta do Museu de Astronomia e Ciências Afins/ Ministério da Ciência e Tecnologia Rua General Bruce, 586

20921-030 - Rio de Janeiro - RJ

Brasil

moema@mast.br
VERGARA, Moema de Rezende. Território e saúde: o estudo de Antônio Pimentel sobre o Planalto Central. História, Ciências, Saúde Manguinhos, Rio de Janeiro, v.15, n.3, p.865-881, jul.-set. 2008.

\section{Resumo}

Apresenta o relatório de Antônio Pimentel, médico da Comissão Exploradora do Planalto Central de 1892. Analisa a parte final do relatório, intitulada Patologia, por tratar-se ali especificamente das relações entre saúde e ocupação do território nacional.

Palavras-chave: território; saúde; climatologia; Brasil, século XIX.

\section{Abstract}

The article presents a report by Antônio Pimentel, physician with the 1892 Central Plateau Exploratory Commission, and analyzes its closing section, entitled "Pathology," which addresses the relations between health and the settlement of the Brazilian territory.

Keywords: territory; health; climatology; Brazil; nineteenth century. 
$\mathrm{N}^{\mathrm{s}}$ final do século XIX, a recém-instaurada República tinha em suas mãos uma nação de proporções continentais, herdada da monarquia, mas os conhecimentos geográficos a respeito desse território eram ainda bastante lacunares e havia o sentimento generalizado de necessidade de maior integração entre o litoral e o interior. Talvez por isso mesmo, na primeira Constituinte republicana decidiu-se formar uma comissão que deveria levar a capital federal para o interior do país: a Comissão Exploradora do Planalto Central, de 1892, chefiada por Luiz Cruls, então diretor do Observatório Nacional. Essa decisão seria uma tentativa de realização do desejo de transferência da capital para o interior, como foi expresso em um artigo de Hipólito da Costa publicado em 1808 no Correio Brasiliense. Durante o Império, o mais ardente defensor dessa idéia foi Varnhagen, que desde 1839 expunha as vantagens de uma capital no interior em uma carta ao Instituto Histórico e Geográfico Brasileiro e retomou o tema no Memorial orgânico, de 1849. Varnhagen ainda voltou a ele em um texto de 1877, que narrou sua viagem ao sertão em direção a Goiás. Em seu retorno a Viena, onde era embaixador, o historiador escreveu A questão da capital: marítima ou no interior?, onde afirmou que tinha encontrado o lugar determinado pela própria Providência para a nova capital, que era formado pelas três lagoas, Formosa, Feia e Mestre-de-Armas, as quais manam águas para os rios Amazonas, São Francisco e Prata.

Os principais motivos para a mudança da capital, defendida pelo historiador, seriam basicamente a segurança - uma capital marítima ficaria à mercê das esquadras inimigas -, a salubridade e a maior integração da corte com as demais províncias. A decisão da Constituinte recuperou os argumentos de Varnhagen e organizou uma comissão que teria a dupla função de demarcar o local de transferência da futura capital (na mesma área sugerida pelo historiador anos antes) e conhecer os vários aspectos geográficos, verificando as condições climatológicas e higiênicas da região explorada. Assim, o artigo 3o da Constituição de 1891 decretou, por proposição do delegado catarinense Lauro Müller, que a futura capital federal fosse transferida para o Planalto Central da República. Para acatar essa decisão, a comissão foi organizada pelo Ministério da Indústria, Viação e Obras Públicas, que destinou para a missão o montante de 350:000\$000. O texto constitucional já determinava uma área de $14.400 \mathrm{~km}^{2}$ para a nova capital, ou seja, dez vezes o tamanho da capital federal no Rio de Janeiro.

Em 1892 Cruls cercou-se de dois astrônomos, Oliveira Lacaille e Henrique Morize, ambos do Observatório Nacional, além do médico higienista Antônio Pimentel, do geólogo Eugênio Hussak e do botânico Ernesto Ule e partiram para o Planalto Central. A expedição, que durou de junho de 1892 a março de 1893, foi equipada com teodolitos, aneróides, bússolas e podômetros, instrumentos meteorológicos e material fotográfico. ${ }^{1}$ Em Uberaba organizouse a entrada no sertão, que tinha como meta Pirenópolis, em Goiás; lá chegando deu-se o início da expedição, em $1^{\circ}$ de agosto.

Para delimitar a zona da futura capital, Cruls optou por adotar o método de determinação das fronteiras dos estados empregado pelos Estados Unidos, produzindo assim um quadrilátero, localizado em torno dos $15^{\circ}$ aos $16^{\circ}$ de latitude sul e por volta de $47^{\circ}$ a $49^{\circ}$ de longitude oeste, em detrimento do método irregular, que toma como referência os sistemas orográfico e hidrográfico e por isso seria mais demorado e custoso. O método adotado levava em consideração as latitudes de dois arcos de paralelo bem como a longitude 
de dois arcos meridianos. Ele também permitiria um maior controle da exploração, pois seria possível verificar, a todo tempo, a posição exata no terreno por meio da aferição dos instrumentos de astronomia.

Assim, Cruls dividiu a comissão em quatro equipes, que deveriam caminhar em direção aos vértices do quadrilátero já determinado e depois retornar ao ponto inicial. Todos os itinerários percorridos pela comissão foram levantados pelo processo americano de caminhamento, servindo-se do podômetro, da bússola e do aneróide, que permitiu não só a verificação das coordenadas, mas a exploração do terreno (Vergara, out.-dez. 2006).

Se a efetiva transferência da capital teve que esperar até a segunda metade do século XX para se concretizar, o caráter de 'descobrimento' do Planalto Central pela Comissão foi desde cedo reconhecido. Nesse sentido, podemos citar o livro Nouvelle géographie universelle, de Elisée Reclus (1894), que já trazia referência ao recém-lançado Relatório Cruls no capítulo sobre Goiás. Durante a expedição, os jornais sempre informavam sobre os avanços dela, principalmente o Jornal do Commercio, que publicou, em 28 de agosto de 1892, uma carta de Cruls: "Aqui chegamos [em Pirinópolis] sem novidades, no dia 1o do corrente ... , e daremos logo começo ao trabalho de exploração". Assim, os leitores do 'litoral' podiam manter-se atualizados sobre cada passo da Comissão e consumiam avidamente notícias de várias expedições que ocorriam no Brasil, fosse por nacionais ou por estrangeiros que por aqui passavam. Para aqueles homens, a definição do caráter nacional passava necessariamente pelo conhecimento preciso do território.

Após a conclusão dos trabalhos da Comissão e a publicação do Relatório Cruls, as notícias sobre a expedição não cessaram. Encontram vida na Revista do Instituto Histórico e Geográfico Brasileiro até os anos 1910, nos artigos de Antônio Martins de Azevedo Pimentel, médico higienista da expedição e membro do Instituto.

Filho de importante família de fazendeiros da região fluminense, formou-se em medicina pela Faculdade do Rio de Janeiro, foi secretário da Comissão de Saneamento do Rio de Janeiro, diretor do Laboratório Bacteriológico Federal, sócio do Instituto Histórico e Geográfico Brasileiro e professor da Faculdade de Odontologia e Farmácia de Ribeirão Preto, onde faleceu em 1928 (Miranda, 1985).

A leitura dos artigos de Pimentel sobre a expedição nos deixa perceber o grande impacto que a viagem lhe causou: "Tive em minha vida a feliz ocasião de visitar as terras elevadas do Brasil central ... e pus em contribuição os conhecimentos que no correr de alguns anos tenho adquirido na leitura e estudo das coisas que dizem respeito à minha pátria" (Pimentel, 1907, p.262).

Para compor este número especial sobre Caminhos, Comunicações e Ciência da revista História, Ciências, Saúde - Manguinhos, escolhi a parte final do relatório de Pimentel², intitulada Patologia, do relatório da Comissão Exploradora de 1894. Tal recorte se justifica porque nessa parte o autor trata especificamente do tema da saúde e de sua relação com a ocupação do território nacional. As duas questões já se encontram estreitamente ligadas no primeiro parágrafo do relatório de Pimentel: "Todo mundo sabe que o povoamento do Brasil quase que se limita exclusivamente à faixa do litoral ... . Justamente nesta região é a salubridade subordinada, em geral, ao grau do paludismo, visto ser baixa, úmida e quente e palustre toda essa zona" (Pimentel, 2003, p.238). 
Para o médico, o Planalto Central era diferente, principalmente por sua altitude, que produzia temperaturas mais frescas e solos férteis, "tudo enfim, que tem as mais estreitas relações com os progressos materiais de uma grande cidade e com o bem-estar dos seus habitantes" (Pimentel, 2003, p.238). A idéia de que o clima da região era adequado para a instalação de uma próspera cidade corroborava uma das principais conclusões do Relatório Cruls, que afirmava ter sido seu resultado mais importante aquele concernente ao clima da região: "Em resumo, a zona demarcada goza, em sua maior extensão de um clima extremamente salubre, sem que o emigrante europeu não precisa da aclimação, pois encontrará aí condições climatéricas análogas às que oferecem as regiões mais salubres da zona temperada européia" (Cruls, 2003, p.111).

Podemos observar portanto um consórcio de cientistas - médicos e astrônomos trabalhando em conjunto para desmistificar a idéia de que "todo o interior do Brasil ainda hoje passa por ser país doentio, muito quente e mesmo inóspito" (Pimentel, 2003, p.239). Aqueles homens não estavam de todo livres de uma visão pessimista acerca da influência dos trópicos, mas afirmavam que, mesmo nas latitudes de clima tropical, poderse-ia encontrar áreas temperadas, como observara Humboldt, autor largamente citado no Relatório, em sua viagem à América do Sul. Isso se devia principalmente à análise da altitude como importante fator nos estudos da climatologia, juntamente com o estudo das condições do solo e da vegetação, entre outros. Nas palavras de Pimentel (p.256): “A altitude representa um papel importante na modificação dos climas tropicais, temperandolhes o calor, tanto que muitas regiões situadas abaixo do equador ou dele muito próximas têm as temperaturas diminuídas a tal ponto que apresentam médias análogas às dos países temperados da Europa, como se dá com a Argélia, o cabo da Boa Esperança e com as Índias Orientais, etc.".

A relevância atribuída à altitude permite notar que, naquele momento, ainda não se havia descartado por completo a visão negativa acerca de introduzir-se a 'civilização' nos trópicos. A revisão do determinismo climático da nosologia brasileira, por exemplo, só ocorreu alguns anos mais tarde com o movimento sanitarista, que buscou as explicações para as doenças na singularidade patológica e social do país (Lima, Hochman, 1996). O leitor poderá constatar que o texto de Pimentel é permeado de referências neo-hipocráticas, baseadas na relação intrínseca entre doença, ambiente e sociedade (Lécuyer, 1986, citado em Ferreira, 2001, p.208). A esse respeito, é exemplar a condenação, pelo médico da Comissão, da ingestão de alimentos fortemente condimentados, ou do descuido da moça que contraiu pneumonia por lavar a cabeça ao meio-dia.

Importa destacar que o higienismo foi uma preocupação da República, tanto para atrair a imigração européia quanto para resolver o problema da insalubridade da capital federal, que retardava o desenvolvimento econômico do país. Essa já era, em 1884, uma preocupação de Pimentel, que apresentara dissertação Quais os melhoramentos higiênicos que devem ser introduzidos no Rio de Janeiro para tornar esta cidade mais saudável para concorrer à cadeira de professor da Faculdade de Medicina (Miranda, 1985). No contexto dos debates acerca da mudança da capital, a busca por um local salubre ganhava enorme relevância.

Na passagem selecionada do Relatório, revela-se o esforço de Pimentel em afirmar que não havia nenhuma doença endógena na região e que os casos encontrados eram alienígenas 
e decorrentes de outros fatores. Vê-se também o médico se aproximar da escola tropicalista de medicina ao citar, como argumento de autoridade, os médicos Bilharz e Wucherer, cujas teorias parasitárias apóia. Essa escola postulava que a umidade e o calor tinham o poder de exacerbar as doenças então associadas a pobreza, má nutrição, falta de saneamento e comportamento inadequado (Edler, 1999), e tais fatores são mencionados não só no texto de Pimentel, mas nos dos demais membros da Comissão Exploradora, que associavam esses problemas ao passado colonial. Aquela geração se via como portadora do progresso, simbolizado inequivocamente pelas ferrovias, constantemente referidas no Relatório Cruls. Os caminhos naturais do Planalto Central eram os rios, mas a ferrovia permitiria ligar mais facilmente o litoral ao centro do país. Na visão de Pimentel (1900, p.217), as estradas de ferro deveriam ser elétricas, já que "a produção de eletricidade é extremamente fácil" e que "não há de ser, nunca com o carvão de pedra inglês, norte-americano ou outro qualquer de países remotos, com que se há de mover as locomotivas das vias férreas destinas a levar a civilização e a vida ao esplêndido araxá brasileiro".

A construção de nosso território tal como o conhecemos foi um processo dinâmico que contou com diversos fatores ao longo da história, entre ações do Estado, expedições científicas e implementação de novas tecnologias como a estrada de ferro e o telégrafo. $\mathrm{O}$ que torna o estudo desse processo interessante é analisar como a conquista desse espaço também repercutiu no imaginário e foi importante componente para se pensar não só o Brasil, mas também o brasileiro.

\section{NOTAS}

* Este texto é um desdobramento do artigo "Ciência e história no relatório da Comissão Exploradora do Planalto Central na Primeira República" (Vergara, out.-dez. 2006). Agradeço a Rafael Winter Ribeiro e a Dominichi Miranda de Sá pelas generosas contribuições ao texto e ao CNPq pelo apoio à pesquisa.

${ }^{1}$ Para uma análise das fotografias da expedição, ver Andermann, 2004.

${ }^{2} \mathrm{O}$ relatório de Pimentel é composto das seguintes seções: O Planalto Central do Brasil ou da América do Sul; Orografia e hidrografia; Geografia; Riqueza mineral, florestal e botânica; Águas medicinais; Descrição topográfica de uma parte do planalto e da área demarcada; Meteorologia; Climatologia da área demarcada; Patologia. 


\title{
A N NEXO IV
}

\author{
O Planalto Central do Brazil ou da \\ America do Sul
}

Todo o mundo sabe que o povoamento do Brazil quasi que se limita exclusivamente á facha do littoral, com o extenso desenvolvimento desde o Rio Grande do Sul á embocadura do Rio Amazonas.

Justamente nesta região é a salubridade subordinada, em geral, ao gráo do paludismo visto ser baixa, humida, quente e palustre toda essa zona.

Nas terras altas do interior tudo é differente.

E' exuberante a fertilidade do solo; a salubridade proverbial; grande a abundancia de excellẹnte agua potavel; rios navegaveis; extensos plainos sem interrupções importantes; soberbas madeiras de construç̧ão de suas grandes florestas; abundancia de preciosos mineraes e essencias diversas; elevação do terreno determinando um menor gráo de seccura atmospherica e uma temperatura mais fresca do que á primeira vista se poderia suppor, em face da sua latitude geographica; tudo, emfim, que tem as mais estreitas relações com os progressos materiaes de uma grande cidade, e com o bem estar dos seus habitantes 
Infelizmente, porém, tudo isto é desconhecido, e todo o interior longinquo do Brazil ainda hoje passa por ser paiz doentio, muito quente e mesmo inhospito.

Entretanto, o contrario é que é exacto, e do que se segue claramente deduz-se que a natureza fez desigual a repartição dos beneficios do solo do Brazil (cumo em toda a parte), e os primeiros poroadores desconhecendo a sabedoria desta distribuição, preferiram as regiōes menos ferteis e menos salubres na comprida e estreita zona do littoral, sem duvida pela maior facilidade do commercio maritimo e das relações politicas com a an. tiga metropole e o resto do mundo civilisado.

Os chapadōes do Brazil Central sobrelevam os da Europa Central e Meridional, approximam-se dos da Africa Meridional, não attingem os da Asia nem os da America, dentro dos limites andinos.

A Suissa, a Saboia e o Tyrol são conside. rados paizes mui elevados; mas, esta opinião è fundada sobre o aspecto que offerece o gru. pamento de grande numero de cumes perpetuamente cobertos de neve e dispostos em cadeias muitas vezes parallelas á cadeia ceratral. Os cimos dos Alpes elevam-se a 3.900 e mesmo ${ }_{7} \cdot 70{ }^{\circ}$ metros de altura, ao pass o que as planicies visinhas do Cantão de Berne não tem mais de 400 a 600 metros. Esta primeira ele vaçāo muito mediocre póde ser considerada como a da maior parte das chapadas de extensão consideravel na Suabia, Baviera e Silesia, perto das nascentes do Wartha e do Piliza.

Na Hespanha, o solo das duas Castellas tem um pouco mais de 58 metros de elevação; e em França, a chapada a mais elevada, é a de Auvergne, sobre a qual repousam - Mont Dore, o Cantal, o Puy de Dome, etc. e cuja elevação, segundo Leopoldo de Buch, é de 720 metros.

Estes exemplos provam que, em geral, na Europa, os terrenos elevados, que apresentam o aspecto de planicies, não tèm mais de 400 a 800 metros de altura acima do mar.

Do Cabo da Boa-Esperança até $2 I^{\prime}$ de látitude austral, o solo da Africa, conforme as observações de Gordon, se eleva insea sivelmente até 2.500 metros.
Todo o chapadão africano, ao norte do parallelo de $3 \mathrm{r}^{\circ}$ habitado pelos Betchouanas, os Korannas e os Bosjesmans, tem cerca de 800 a 900 metros acima do nivel do Oceano; e esta altura, com pequena differença, póde ser considerada a mesma em Angola Central, para baixar um pouco no Estado Livre do Congo, constituido, por assim dizer, só pela vasta e pouco elevada bacia do Rio Congo.

$\mathrm{Na}$ Asia tem-se prestado mais attenção aos picos e ás gargantas ou passagens das cadeias de montanhas do que, propriamente, às planuras elevadas Entretanto, comorefere Humboldt, entre os parallelos de $34^{\circ} \mathrm{e}$ $37^{\circ}$ de latitude boreal encontram-se chapadas analogas às do Mexico, e acredita este notavel naturalista que a altura média das chapadas comprehendidas entre o Himalaya e o Kouen-Lun não vae além de 3.500 metros; mais ao norte, o grande deserto de Gobi, segundo o Padre Duhalde, não attinge a 1.400 metros. Mas, Schrader diz, que a região do NW da China fórma um enorme chapadão in. terior, completamente cercado de montanhas, e que sob a fórma de grandes terraços vem descendo por degráos da vertente septentrional do Himalaya, onde se acham em uma altitude média de 4.000 metros, passa pelo Thibet com 3.000 a 3.500 metros até a grande superficie ligeiramente concava que forma o deserto de Gobi e as esteppes da Mongolia, cujo nivel inferior não vae abaixo de 900 a r.100 metros.

Nos Estados Unidos, na regiăo comprehendida entre as Montanhas Rochosas e a cadeia littoral da California, extende se uma intumescencia do solo, de 1.800 a 2000 metros de altura, formando o que o capitão Fremont e Walker chamaram a grande bacia.

E' um vasto terreno arido, pouco habitado, não interrompido por accidente algum, cheio de lagos salgados, dos quaes o maior tem a altitude de 1.280 metros e communica com um menor, o Yuta, que recebe um rio abun. dante, denominado Timpanogo.

$E^{\prime}$ palpavel o contraste entre estas terras elevadas do occidente norte-americano $e$ as planicies baixas, ligeiramente onduladas, bastante regadas, ferteis. cheias de habitantes, proximas do Mississipi, entre as Montanhas Rochosas e os Alleghanys, cujos vertices, o 
monte Washington e o monte Marcy, segundo Lyell, levantam-se a 2.02 ; $~ x .642$ metros; sendo que a maior parte dessas terras baixas attinge apenas á elevação variavel de 138 a 195 metros.

Em geral, o chapadão mexicano, de direç̧ãonorte-sul, é tão pouco interrompido por valles, tem o declive tão brando e uniforme, que em distancia superior a 800 kilometros o solo conserva-se com a aitura entre 1.7 ro e 2.700 metros sobre o nivel do Oceano visinho.

Este chapadão inciina-se insensive!mente para o norte até os Estados Unidos, e para o sul tambem; mas, para o oeste, para Acapulco, Tepic, etc, e para léste até Vera-Cruz, a descida é mais rapida e durante muito tempo servio de serio obstaculo ao desenvolvimento do paiz.

Com o rapido progresso do Mexico, as difficuldades de transporte desappareceram com a construcção de uma linha ferrea que partindo de Vera-Cruz e Alvarado, vae à cidade do Mexico, e d'ahi, seguindo a geral direç̧ão longitudinal do chapadão, procura os Estados Unidos, onde penetra, com a altura de $I 148$ metros, na chapada de La Sierra Madre, no Novo Mexico.

Na America Meridional a Cordilheira dos Andes, a principio dividida em tres ramos, (o oriental, o central é o occidental) reduz-se depois a dous no Equador e Perú, e assim continúa com afastamentos differentes ałé ás proximidades do vulcão Copiapo, mais ou menos, entre a provincia chilena de Atacama e a argentina de Catamarca, onde de novo forma um só systema até ás terras de Magalhães.

Por toda a parte a Cordilheira é cortada e interrompida por fendas semelhantes a filōes abertos e não obstruidos por substancias heterogeneas.

Se ha plainos de 2.700 e 3.000 metros, como no Equador, Colombia, Bolivia, etc., são de pequenas dimensōes, podendo mesmo ser antes considerados como valles limitados pelas cordilheiras secundarias, cujos picos mais elevados constituem as cristas dos Andes tambem.
Os valles transversaes do Perú e da Culombia, mais do que os das outras republicas sul-americanas, tèm ás vezes profundidade vertical de 1.403 metros. Isto até hoje tem im

pedido, talvez, a construcção de vias ferreas transandinas nesses paizes, obrigado os viajantes a andar só a cavallo ou ás costas dos indios chamados carregadores, e reduzido a nada a exportação agricola, mineral, ou outra, para as regiōes orientaes pela impossibilidade do transporte.

Pela succinta descrip̧̧̃o que fiz de divers’s plainos do mundo. em c mparação com o nosso Planalto, conforme o exposto neste livro, se inferirá a incontestavel superioridade deste, visto que das tres zonas em que que Humboldt dividio a America Meridional, as duas, do norte e do sul, são esteppes e planuras hervosas, de pouca altura; em quanto a do meio, de um lado em contacto com a da serra de Parima e do outro com o systema das elevadas montanhas do Brazil, póde ser considerada como uma planura selvatica, que na porção mais elevada tem a altitude média de r.00o metros sobre o nivel do mar, e dimensões iguaes a quasi tres vezes o territorio de toda a Republica Franceza.

A conformação physica e climatologica do vasto planalto central do Brazil, facilita sobre-maneira a acclimação do trabalhador europeu, sem os prejuizos das regiōes torridas, cujos predicados ahi desapparecem pela grande altitude média; pelos seus rios navegaveis brandos declives favorece 0 movimento cemmercial interno e as demais relaçōes dos Estados brazileiros entre si e do Brazil com as republicas visinhas; a America do Norte, a Europa e a Africa, bem como garante ao Governo Federal innumeros pontos estrategicos para a defeza militar do Dis. tricto.

A fertilidade do solo combinada com a altitude, etc., concorre para o bom exito na cultura do frumento, como em minima escala se observa perto de Cavalcanti ao norte. do Estado de Gujaz; e todas as plantas da zona temperada poderão bem se acclimar nesta região. 
A menor c a maior maxima foram respecti vamente $24^{\circ} .0$ e $31^{\circ} .5$, com a méclia de $29^{\circ} .2$, senclo que a média geral foi de $24^{\circ} .2$. A menor temperatura do ar foi de $20^{\circ} .5 \mathrm{e}$ a maior $28^{\circ} .0$.

A pressão atmospherica tem a média de $717^{\mathrm{mms}} 9$ e a humidade relativa $71^{\circ} .4$.

Do dia 20 a 25 choveu constantemente até o meio dia do ultimo, ora de manhã só, ora de tarde, ora todo o dia, conservando-se o céo sempre. na sua quasi totalidade, coberto de nim bus, cumulus-nimbus, cumulus e cirrus, sob a influencia invariavel dos ventos $\mathrm{W}$, NIV - NE.

\section{Climatologia da área demarcada}

Vis diversas tabellas do capitulo anterior estão expostos, embora mui resumidamente, us principaes elementos, cujo exame comparativo basta para tornar conhecido o clima de uma parte do Districto Federal, cuja generalisação póde caber tambem a toda a áreat c quiçá a maior extensão ainda, uma vez que muito além dos limites do futuro Districto se encontram em todos os lados, os mesmos attributos mesologicos.

Procurei particularisar esta resenha, porque o clima local é o unico cujo estudo pratico offerece, na actualidade scientifica, um interesse real, pois que da reunião das diversas influencias locaes, como sejam a altitude, a configuração do solo, a vegetação, etc.. com a acção de alguns meteoros, se infere com segurança o caracter da zona estudada.

Esta cxposição $\dot{c}$ a que a hygiene dere considerar em primeiro logar porque ella di os mais praticos resultados ! Jousset ${ }_{j}$.

É acceito em climatologia que a zona dos climas de altas temperaturas nada mais rcpresenta do que uma serie de climas par. ciaes differindo entre si por caracteres bem decisivos ! Dutroulau). Foi pensando como este grande medico, sem duvida, que J. Rochard deu a seguinte definição de clima: "it reunião das superficies do globo que representam as mesmas condiçổes physicas e que reagem do mesmo modo sobre a saude de seus habitantes."
Toda a superficic do Districto, perto, porém fóra da latitude dos climas torridos ou hyperthermicos, segundo a denominação de Fonssagrives, acha-se entre a linha isothermica de +25 e a de +15 , na zona dos climas quentes ou thermicos, onde o sol, o soberbo dominador dos tropicos, na conhecida phrase de Buffon. excede a todos os outros agentes climatericos.

Collocado no interior do Brazil; muito afastado do equador thermico, que passa além das costas septentrionaes da America do Sul, nas Antilhas; fazendo parte integrante das grandes planicies que participam do fresco $e$ do agradavel das cacleias de montanhas interiores do continente e bem exposto á acf̧ào dos differentes elementos meteorologicos, o Districto Federal recebe igualmente o beneficio do aquecimento solar, ora nas partes superiores ora nas inferiores, dos accidentes do solo, sem os damnos do excessivo calor, devido já à sua altitude média, já ao manto de relva que durante grande parte do anno furta a terra á acção directa dos raios sola. res, sem enumerar os capões das cabeceiras, os carrascaes, as mattas e os burytisaes.

É crença corrente e infelizmente partilhada até por homens de alto merecimento scientifico que o interior do Brazil é intoleravel por causa do seu calor abrasador, chegando mesmo Le Roy de Mericourt e Eugenio Rochar a collocar o clima quente do Brazil ao lado do da Arabia, da Tripolitana, onde nunca chove. e do sul de Marrocos, isto é: ao lado do de paizes, cujas altas temperaturas provèm essencialmente dos grandes desertos de areia, sem contar, em relação a Marrocos, a influencia thermogenica dos ventos do Sahara, que, no Senegal, situado ao sul de Marrocos e nas mesmas condições to. pographicas, $\mathrm{faz}$ o thermometro subir em poucos minutos de $+29^{\circ} .0 \mathrm{a}+40^{\circ} .0$ e mesmo $a+50^{\circ} .0$, no dizer de Dutroulau; nas margens do mar Vermelho, Arabia, onde se fazem sentir os ventos dos desertos arabes, A. Roche vio o thermometro se elevár quasi instantaneamente de $+20^{\circ} .4$ a $+40^{\circ} .3$; e na Tripolitana, segundo a citação de $A$. de Fontpertuis, os algarismos das 
temperaturas se mostram muito elevados tambem.

N'esta parte do interior do Brazil, a differença entre a menor minima e a maior maxima observada, foi de $25^{\circ} .0$, o que consti tue um phenomeno excepcional, sendo que a mèdia d'estas oscillações é de $\mathrm{r}^{\circ}{ }^{\circ} . \mathrm{r}$.

$\mathrm{Na}$ Republica Argentina, cuja topographia se asscmelha alguma cousa com a do Districto, com a vantagem ainda do valor uniformisador de temperaturas da vasta extensāo do Oseano Atlantico Meridional, e a cuja latitude, mais ou menos corresponde a altitude do Planalto Central, a difterença é de $39^{\circ} .5$, entre $-2^{\circ} .0$ e $\cdot 37^{\circ} .5$, sendo a mé-

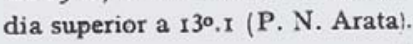

A altitude representa um papel importantissimo na modificação dos climas tropicaes, temperando-lhes o calor, tanto que muitas regiōes situadas debaixo do equador ou d'elle muito proximas, têm as temperaturas diminuidas a tal ponto, que apresentam médias analogas ás dos paizes temperados da Europa, como se dá com a Argelia, o Cabo da BoaEsperança e com as Indias Orientaes, etc.

Tem-se procurado estabelecer uma lei mathematica para essa relação da temperatura com a altitude, e mesmo Humboldt chegou a admittir que a cada ascensảo de 156 a 170 metros correspondia, na Europa Central entre os parallelos $38^{\circ}$ e $71^{\circ}$, o decrescimento de um gráo thermometrico.

Com os progressos da thermometria climatologica, sensivel impulso tem obtido o conhecimento da distribuição do calor na superficie da terra, pelo estudo das inflexões e distancias das linhas isothermicas e isothericas, nos diversos systemas de temperaturas a léste e a oeste da Asia, Europa Central e America Oriental, o que, em summa, permittiu estabelecer a seguinte questão (Humboldtj: "a que fracção do calor thermometrico médio do anno ou do verão corresponde uma variação de um graio em latitude ‘uando se desloca em um mesmo meridiano?"

Qualquer que seja, porém o systema de linhas isothermicas de iguaes curvaturas, existe necessaria e intima ligação entre os tres seguintes elementos: diminuição do calor no sentido vertical e de baixo para cima; variação de temperatura para um gráo de mudança na latitude geographica; e a relação que existe entre a temperatura média de uma estação em uma montanha e a distancia ao polo de um ponto situado ao nivel do mar.

Entre os parallelos de $38^{\circ}$ e $71^{\circ}$, diz Humboldt, a temperatura decresce uniformemente na razão de meio gráo do thermometro para cada gráo de latitude. Mas, de outro lado, como o calor diminue de $\mathrm{I}^{\circ}$ nesta regiāo quando a altura cresce de 156 ou r;o metros, resulta que 78 ou 85 metros de elevação acima do nivel do mar produzem o mesmo effeito sobre a temperatura annual como o deslocamento para o norte de um gráo de latitude. Assim a temperatura média annual do convento do monte São Bernardo, a 2.491 metros de altura na latitude de $45^{\circ} 50^{\prime}$. corresponde á de uma planicie a $75050^{\prime}$ de latitude.

No systema da America Oriental, a temperatura média annual varia, das costas do Lavrador a Boston, de $0^{\circ} .88$ por cada gráo de latitude; de Boston a Charlestown de $0^{\circ .95}$; desta cidade ao tropico de Cancer (Cuba) a variação desce a $0^{\circ} .66$. Na zona tropical, a temperatura varia com tanta lentidão que de Havana a Cumana a mudança, para um gráo de latitude, nảo vai além de $0^{\circ} .20$.

Todas estas observações, como claramente se vé, foram feitas ao nivel do mar, ou com pouca differença desse nivel.

As observações feitas por Humboldt, na parte intertropical da Cordilheira dos Andes, deram a diminuição de um gráo de temperatura para cada 187 metros de augmento na altura. Trinta annos mais turde. Boussingault achou, termo médio, r 75 metros. Trabut julga mais consentaneo dizer que a meteorologia de um logar é modificada pela elevação do terreno, que a altitude representa um factor consideravel na differenciação dos climas parciaes, sem comtudo, precisar exactamente o seu valor, e resume dizendo que, a partir de 1.000 a r.200 metros, o clima tornase muito semelhante ao da Europa Central.

Esta opinião de Trabut é corroborada pelo facto da diminuição da temperatura á medida 
que se eleva sobre o nivel do mar, no sentido da vertical.

Para a diminuição de cada um grảo de calor, segundo Lombard, é necessaria a elevação cle 166 metros. na média.

Os irmãos Schlagintweit acceitam esta média referida aos Alpes Europeus; porém Gaudier, baseando-se em quatro annos de observação, crê que a altura a que se deve chegar para obter o abaixamento de temperatura cle um gráo é de $186^{\mathrm{m} \cdot} \cdot 2$, termo medio.

Kaemtz diz que, em geral, póde-se admittir que a temperatura decresce de um gráo por 185 metros: mas, este numero varia com a latitude, a estação e a hora do dia, pois que o decrescimento ė mais notavel no verão do que no inverno, depois do meio dia do que de manhã, etc.

Partindo do que acabo de dizer, e applicando ao futuro Districto Federal, na latitude de $15^{\circ} .16^{\circ}$ e altitude média de 1.000 metros. vè-se que a latitude é comparavel com as das regiōes situadas entre $29^{\circ}$ e $30^{\circ}$, e a temperatura média oscilla entre $18^{\circ}$ e $20^{\circ}$.

A elevação da temperatura não alcança, pois, tão alto gráo, que possa dar á região estudada o caracter da região torrida, o que importa dizer que o gráo de humidade atmospherica não attinge os mesmos algaris. mos das regiões baixas e humidas, ou da zona do littoral.

Para esse estado de humidade concorre tambem a natureza do terreno que é em parte constituido por uma camada, de espessura variavel, de grés argiloso, ou argilo-ferruginoso, ora sobreposta ora sotoposta a camadas de cascalho de quartzo rolado e de um conglomerado limonitoso (canga), dando idéa de que immediatamente abaixo d'estas alluviōes se acham, ou horizontal ou obliquamente, o schisto micaceo, a argilla, o steachisto, etc., como de facto, se verifica em muitos pontos. $\mathrm{O}$ solo assim composto, com a orientação e as inclinoçōes apontadas, facilita singularmente a expedição das aguas superficiaes e a prompta evaporação das infiltradas.

Com o augmento da temperatura nos mezes cie verão tambem a capacidade da absorpção do ar para o vapor d'agua augmenta, razão pela qual durante os mezes de Maio a Agosto só raramente è que o céo apresenta nurens, ao passo que com a approximação do mez de Setembro, e sobretudo de Outubro em deante, vão apparecendo, atravez dos densos nevoeiros seccos produzidos pela fumaça accu. mulada dos prejudiciaes incendios dos campos, pequenos cirrus e stratus até que o estabelecimento dos ventos de $\mathrm{NW}$ venha iniciar o periodo das chuvas, que nesta parte do interior do Brazil tem particularidades dignas de nota.

Com o accesso do sol ao zenith, coincide a vinda do cortejo da abobada de nuvens, elevação de temperatura, humidade, etc., que o acompanha na sua marcha entre os tropicos, dando variações accidentaes, que modificam sensivelmente o caracter do clima. de uma época parà outra.

No tempo secco, a temperatura baixa manifesta-se pela quéda do orvalho immediata. mente após o occaso; este or valho muitas vezes é tão abundante que molha os telhados das casas e mesmo chega a gottejar e outras, felizmente raras, transforma-se em geada mais ou menos intensa, duradoura e damnosa.

Os ventos deste periodo do anno são fra$\cos$, seccos e frios e quasi sempre vêm dos rumos de $\mathrm{E}, \mathrm{SE}$ eS, depois de terem, os dous primeiros especialmente, atravessado larga superficie plana de paiz secco, e terem transposto as cadeias de montanhas da Serra da Canastra, da Matta da Corda e suas ramifi. cações, e da Serra Geral que para o norte se dirige com diversos nomes.

No periodo das chuvas são estes ventos substituidos pelos ventos equatoriaes, quentes e humidos, de origem maritima e direcção N-S atravez das extensas planicies, quasi sem accidentes, regadas por numerosos e cauda. losos rios com affluentes em numero infinito, comprehendidos entre o Amazonas, ao norte, e a Serra Geral, ao sul.

Mas, em virtude da rotação da terra, os referidos ventos chegam ás regiōes centraes do Brazil pelo rumo de NW acompanhando-se não poucas vezes de tormentas e borrascas.

Assim aquecidos e sobrecarregados de vapor d'agua, os ventos se elevam na atmos- 
phera resvalando pelos planos inclinados ou encostas das terras altas do interior, e, pela dupla razão de chegarem a regiōes altas da atmosphera com temperaturas inferiores ás suas e de se dilatarem em virtude de mais fraca pressão do ar, a humidade se-condensa e formam-se as nuvens, ao mesmo tempo que grande producção de electricidade tem logar; e é no meio de relampagos e trovões que es. tas nuvens, quasi sempre,se de sfazem em diluvianas chuvas tão communs no interior do Brazil; de Outubro a Março.

Propositalmente me extendi sobre a altititude, temperatura, humidade relativa, chuva e ventos, e deixei em segundo plano a pressão barometrica, que no caso vertente pouco exprime em face da altitude média da zona estudada, a tensão do vapor, etc., que representam na constituição dos climas, papel menos importante a despeito da opinião de Borius e Treille, que acreditam que não é sobre a temperatura que devem recahir as accusaçōes pelo facto das sensiveis variaçōes de calor e de frio, que experimenta o corpo humano, e, sim, sobre as oscillações dos hydrometeoros, especificadamente da tensão do vapor d'agua ou humidade absoluta.

\section{Pathologia}

Nenhuma affecção constante da pequena estatistica por mim organisada, é particular á parte do Estado de Goyaz visitada pela Commissão, e nem tão pouco depende do clima.

As molestias alli indicadas, entre as quaes algumas graves, como a syphilis, a bouba, a morphéa e diversas outras em que a anemia predomina, observam-se tambem em varios pontos de toda a zona intertropical em me. dida desigual para as differentes raças, para os differentes gráos de receptividade morbida individual, e, bem assim, para as influencias mesologicas, etc.

A isto, de certo, não são estranhas a altitude média dos chapadões, que tambem o é do da America do Sul; a excellencia das condiçōes meteorologicas e atmospherologicas; a constituição do solo até hoje absolutamente inclemne do paludismo; a grande abundancia e pureza da agua potavel, etc.
Ao contrario do que se dá coin a geographia botanica, a geographia medica è mui pobre e mui imperfeitamente póde, mutatis mutandis, recordar a maior variedade relativa da flora goyana.

Outrosim, o cunho pathologico da região do norte, especialmente das vertentes dos rios caudalosos e de curso lento, ainda maior sim. plicidade acarreta a estatistica nosologica, pois que o paludismo domina a pathogenia de toda a porção boreal do Estado, em que o solo é baixo e formado por terrenos de alluvião recente, como se nota na grande facha florestal que corre entre Pyrenopolis e Goyaz, conhecida geralmente pela denominação de matlo-grosso, e que constitue uma parte importante da vasta bacia do Alto Araguaya.

Como se vê, de $r_{4} 6$ doentes, dos yuaes $8_{4}$ homens e 62 mulheres, sendo adultos $\mathrm{r}_{2} \mathrm{e}$ crianças 14 , soffriam I8 ou $12,3 \%$, de dispepsia gastrica, ou gastro-intestinal com ou sem dilatação do estomago; 33 ou $8,9 \%$, de boubas seccas ou humidas, em diversos gráos de gravidade; II ou $7.5 \%$, de neurasthenia de forma cerebro-espinhal e gastro intestinal; 8 ou $5.4 \%$ de bronchites $e$ broncho-pneumonias; 7 ou $4.7 \%$ de dismenorrhéa ; 5 ou $3.4 \%$ de manifestações agudas da intoxicação syphilitica; 4 ou $2.7 \%$ de hystero-epilepsia, sendo 3 mulheres e um homem; o mesmo numero de leucorrhéa e paludismo chronico e hypoemia intertropicai.

Fntre as enfermidades mais communs em Goyaz, o grupo das venereas occupa um dos primeiros logares, tendo na frente a syphilis, o kallico como lá se diz, debaixo de todas as suas formas clinicas, desde a infecção hunteriana recente até as manifestaçōes terciarias, a heredo-syphilis, c outros effeitos remotos representados por lesōes visceraes graves, etc.

As manifestações agudas da infecção syphilitica dos cinco doentes apontados na estatistica eram, em dous, exacerbaçũes de molestia antiga, e em tres significavam recente contaminação.

Assim tambem os doentes sob a rubrica de lesão cardio-aortica erũo ambos syphiliticos; e um, além disso, soffria de paludismo chronico de forma intermittente. já quasi no declinio cachetico. Apresentava este individuo uma endocardo-arterite proliferante syphili- 
tica tão avançada que o sopro presy'stolico se ouvia a mais de vinte centimetros da parede anterior do thorax, semelhando a um assobio e impedia o doente de conciliar o somno. Applicando-lhe o tratamento especifico, em poucos dias melhorou sensivelmente. $\mathrm{O}$ outro syphilitico tinha um vasto aneurisma da crossa da aorta causando tão profundas perturbações na circulação e nutrição do braço direito, que este já tinha tomado proporções gigantescas em relação ao outro.

Uma das mais interessantes manifestações da syphilis encontrei em um amaurotico que, havia quatro annos tinha deante da vista uma nuvem branca que o impedia de distinguir pessoas e cousas, o qual ficou relativamente curado dentro dos poucos dias em que nos demorámos na Formosa.

Mais communs aincla do que as multiplas variedades das molestias venereas em Goyaz são as que dependem das alterações da nutrição organica, sejam estas alteraçōes devidas ás substancias alimentares, á evolução anormal da digestão em suas diversas phases, ou a vicios e defeitos dos phenome. nos phýsicos ou chimicos, ou aos processos intimọs da nutrição intersticial.

Em qualquer das hypotheses, porém, a modificação da constituição chimica do organismo implica fatalmente a diminuição da resistencia dos meios organicos contra a invasĩo dos agentes da nossa destruição, para os quaes o homem são não é hospitaleiro, na bella e exactia phrase de Bouchard.

$\mathrm{E}$, pois, essa prévia modificação da nutriçào organica representa o franco determinismo de uma rasta serie de molestias differentes, das quaes se destacam: as diversas dispej:sias, a neurasthenia com todas as suas modalidades clinicas, $o$ arthritismo, a anemia, a chlorose, etc.

Muito mais frẹuentes são as affecções gastro-intestinaes idiopathicas, do que as symptomaticas ou protopathicas. Um dos phenomenos mais constantemente observa. dos consistia no desenvolvimento de gazes no estomago e intestinos, com producção de forte tympanismo que desapparecia pela expulsão ou absorção dos gazes, ou comprimia mecanicamente o diaphragma para cima, e produzia subsequentemente oppressão sem. pre penosa, sobretudo durante a digestão.

Nos casos de neurasthenia, os soffrimentos das faculdades intellectuaes eram patentes, e em um doente que examinei manifestavam-se por uma inexplicavel indecisão em suas resoluções.

Muitas vezes o abatimento era devido a meteorismo, ás difficeis eructações, e a um sentimento de tristeza acabrunhadora, que, quando era acompanhado de desarranjos sensoriaes, levava o doente a falsa crença de congestão cerebral, e originava tambem vertigens, cephalalgia, hypochondria, etc.

Facilmente se deduz que este estado de cousas, que acabo de descrever, existindo permanentemente acarreta certográo de desnutrição seguido de anemia, chlorose, etc.

Conheci um neurasthenico, de forma gastro-cerebral, em que a scena morbida apresentava manifestações psychicas apparente mente inquietadoras, e mui interessantes para o neurologista. Semelhante ao maniaco, sempre que áquella cidade (Formosa) ia uma pessoa da Commissão, aprazia-se o nesrasthenico em visitar o recem-chegado, tendo-se previamente perfumado todo e vestido com todo o rigor, e durante a visita achavase tão perturbado, em verdødeiro estado də excitação nervosa, que não podia sustentar a conversação sem grande embaraço de palavra e difficuldade de ideiação.

Tendo de fazer uma viagem ao Rio de Janeiro, sentiu-se possuido de tal nervosismo, que foram de todo infructiferas duas tentativas de iniciação da dita viagem. Para realizal-a foi mister sahir incognito, e, só a mai de meio caminho, é que se soube do destino tomado.

E', portanto, nas molestias deste grupo que avultam em numero as variedades, devido, em geral, á alimentação impropria de grande parte dos habitantes particularmente além dos limites ethnographicos marcados pela popula. ção mineira.

A natureza das substancias alimentares; o abuso dos condimentos fortemente excitantes, alguns mesmo irritantes, pelo que se tornam verdadeiros causticos do estomago 
e intestinos; o pouco cuidado que se tem na escolha da agua para beber; e a geral falta das elementares noções de hygiene privada concorrem directamente para o apparecimento de algumas das doenças que acabo de citar.

Apezar de ser a região abundantissima de excellente agua potavel, em geral a do uso commum é má, ou porque é colhida em pontos ruins, ou porque antes de chegar ao logar do consumo, tem atravessado chiqueiros de porcos, curraes de gado, etc., ou em fim, porque é tirada de uma pequena bacia cavada no chão, não obstante passar um corrego ou um ribeirão distante algumas dezenas de metros apenas. A infecção palustre, que na opinião de todos os medicos é a nota caracteristica da pathologia intertropical, é excepcionalmente rara na região destinada a receber a futura Capital, e a que constitue a raridade excepcienal póde desapparecer em curto lapso de tempo, dependendo apenas de insignificantes trabalhos dc saneamento de alguns rios e deseccamento de alguns brejos.

Os seis casos constantè da estatistica são todos exoticos, isto é, dous são de doentes encontrados na minha viagem de Caldas Novas de Goyaz á cidade de Bomfim ; tres são do Vão do Paranan, e o ultimo contrahio a molestia em um pantanal do ribeirão $\mathrm{Ca}$ riru, com as nascentes na Serra do Mestre d'Armas, affluente do Rio Jardim que desem. boca no Rio Preto. Este vai ter no Paracatú e o Paracatú no São Francisco.

Segundo intormaçōes de pessoas que merecem té, ha quarenta annos, houve uma epidemia grave e mortifera de malaria nas margens do Rio Corumbá, após extraordinaria enchente, epidemia que não passou para cima do porto do Pechincha.

N'aquelle porto, foram atacadas durante a referida epidemia, de preferencia, as pessoas que, aproveitando os poços abundantes de peixes na retirada das aguas, iam nelles pescar e se expunham sob os raios solares ardentes a contrahir facilmente a doença; as que imprudentemente se banhavam nas aguas estagnadas e lodosas do rio transbordado, etc.
Dos affectados, em numero de sete nesse porto, tres falleceram durante a evolução da molestia, dous restabeleceram-se e os restantes vieram a fallecer cacheticos, após tres annos de continuos soffrimentos.

Em toda a área demarcada, só ha um logar, esse mesmo muito pequeno, em que observei pantano. Foi perto da villa de Mestre d'Armas, no rumo dos morros do Catingueiro, na planicie humida que acompanha as sinuosidades do ribeirão do mesmo nome, e onde se havia installado, por occasião da nossa passagem, o novo ceiniterio, contra tudo - que a sciencia e o senso commum inclicam; sendo de notar que o minus. culo pantano promptamente desapparecerá desde que o curso do ribeirão fôr livre, e desembaraçado o leito dos innumeros troncos e raizes de arvores que o atranvacam em todos os sentidos.

Entretanto, em Mestre d'Armas não se conhece a febre palustre, e o aspecto da $\mathrm{p}$ ). pulação, na sua quasi totalidade mui pobre, é indicativo de boa saude.

Fóra do futuro Districto, a Lagôa Feia, que mais é uma expansão ovalar do Rio Preto, tres kilometros abaixo da sua nascente dentro da cidade da Formosa, póde ser desseccada pela colmatagem ou pela mudança do curso do rio. entào pequenino corrego, e larga abertura da extremidade meridional da Lagôa para o seu franco e completo esgoto.

O começo do mal afamado Vão do Para. nan, em que se acha o vertice $\mathrm{NE}$ da área, é perfeitamente salubre como a Commissão verificou, e como palustre só existe na imaginação do ignorante ou em alguns dos muitos infundados preconceitos populares, tão abundantes em quasi todos, senão em todos os logares atrazados.

E' corrente em todo o sul de Goyaz, que na época do começo dos ventos boreaes, succedem-se casos de bronchites, bronchopneumonias, pneumonias, etc., originados, regra geral, pelos descuidos pessoaes, etc.

Uma mulhèr adoeceu gravemente de pneumonia, comprehendendo a totalidade dos dous pulmões, por haver lavado a cabeça 
em uma bica d'agua corrente, ao meio dia; tendo o corpo bunhado de copioso suor, em consequencia de serviço que fazia perto do fogo.

Este resultado é tanto mais natural, quanto tivemos na Commissão um exemplo claro do que vale o cuidado, visto que a despeito da muita bondade de um clima, os abusos, todavia tèm mais força para produzir $\circ \mathrm{mal}$ do que o clima para o evitar.

Foi o caso de um dos nossos mais distinctos companheiros, que soffrenclo ha longo tempo de uma pharyngite granulosa. conseguio atravessar todos os mezes de frio e secca e os de cabrechura sem o menor incommodo; isto é mais uma prova de que aos effeitos physiologicos do clima de regiōes como a explorada, se junta o de grande força de resistencia da, maior parte das pessoas nelle residentes contra os resfriamentos (Weberj.

- A dismenorrhéa, cujas fòrmas predomi. nantes foram a congestiva e nevralgica originou-se principalmeute na falta de cuidado na ultima phase de puerperio, ou nas épocas do fluxo catamenial; e nâo foram outras as razỏes pelas quaes pude encontrar esta doença em uma menina de $\mathrm{I}_{4}$ annos.

-A leucorrhéa em grande parte é devida á má alimentaçào, á vida sedentaria de quasi todas as mulheres, e, segundo penso, ao uso das aguas de brejo e de corregos immundos para banhos.

- Dus casos observados, um dos mais curiosos foi o da hemato-chyluria do capitão V. que antigamente teve febres intermitten tes apanhadas no V'ão do Paranan, e soffre actualmente tambem de uma bronchite chronica. Tem tido melhoras duraveis sem comtudo obter até agora cura permanente da hemato-chyluria. Accresce que esta molestia no tempo quente cede mais facilmente á aç̧ão dos medicamentos e recrudesce no tempo fresco, o que está em desaccordo com a theo ria que admitte a acção do calor solar dos tropicos dominando a etiologia e presta, pois, apoio á theoria parasitaria de Bilharz e Wucherer.
-Não é muito raro o papo em Goyaz, e as pessoas que o tem, salio uma ou outra, não ligam a menor importancia à doença.

O papo, em geral indolente, é pediculado ou não. No primeiro caso. a extensão do pediculo varia de alguns centimetros a alguns decimetros e quasi sempre é finn; no segundo, o papo é adherente e se apresenta com formas e dimensões variadas, seja elle uniloculado ou multiloculado.

Algumas vezes, no periodo inicial, dóe a ponto de incommodar o paciente.

Dá em todas as idades e sexos, e de ordinario não tem cura.

Vi em Pyrenopolis um homem que possuia um incipiente doloroso. Acontecendo ir á ciclade de Goyaz, no fim de vinte dias notou que o papo havia desapparecido completamente sem deixar o menor vestigio, para reapparecer com a sua volta para aquella cidade.

A natureza do papo até hoje conserva-se ignorada, mas acredito que não the é extranha a influencia da agua, da alimentação e das intemperies.

-A tuberculose é quasi desconhecida nos sertões, e os dous doentes que encontrei na Formosa eram ambos de fóra, e haviam procurado essa cidade por causa da excellencia do seu clima. Uma moça mineira que anteriormente havia exercido o officio de cigarreira, e um moço vindo de São Paulo por Araxá.

\section{Estatistica pathologica}

ORGANISADA PELO DR. ANTONIO PIMENTEL

Dyspesia.................... I8

Bouba.$\ldots \ldots \ldots \ldots \ldots \ldots \ldots \ldots \ldots$ I3

Neurasthenia..$\ldots \ldots \ldots \ldots \ldots \ldots \ldots$ II

Dismenorrhéa................. 7

Bronchite................... 8

Syphilis .................... 5

Leucorrhéa................... 4

Paludismo..................... 4

Hypohemia intertropical............ 4 


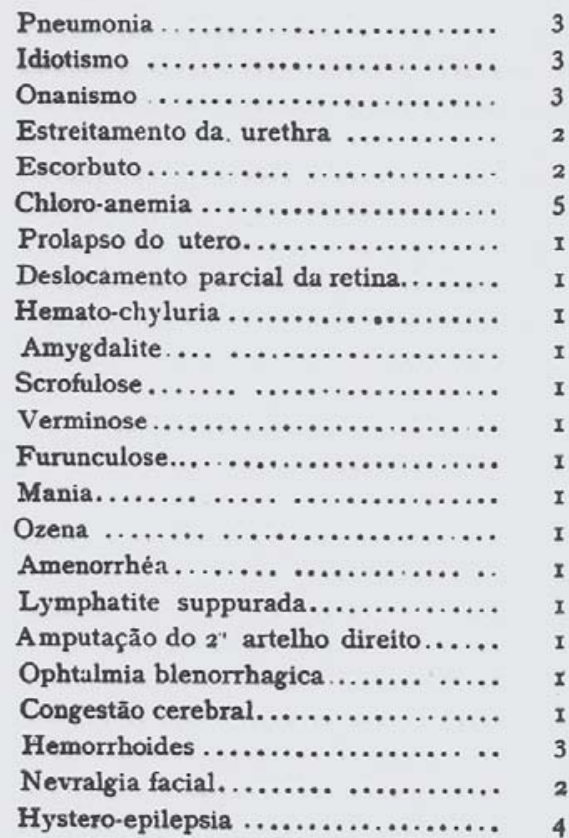

Senectude.................... 2

Dysenteria e diarrhéa.............. 2

Gastrite chronica............... 3

Alimentação insufficiente........... 2

Lesāo cardio-aortica .............. 2

Congestão retiniana $\ldots \ldots \ldots \ldots \ldots \ldots$ I

Metrorrhagia.................. I

Keratite intersticial parenchymatosa... I

Mordedura de cobra.............. , ]

Conjunctivite purulenta............ I

Sclerose lateral em placas ........... I

Polypo uterino. ................ I

Phlebite traumatica $\ldots \ldots \ldots \ldots \ldots \ldots$ I

Congestão pulmonar.............. I

Psoriasis (lepra vulgar) $\ldots \ldots \ldots \ldots \ldots \ldots$ I

Hepatite traumatica.............. I

Retenção de placenta............ I

Gonorrhéa...................

Tuberculose pulmonar............. 2

Herpes ulcerada $\ldots \ldots \ldots \ldots \ldots \ldots \ldots$ I

Facada ................... I

Tiro de garrucha.............. I

Dr. Antonio Pniznter,

Medico hygienista da Commisetio 


\section{REFERÊNCIAS}

ANDERMANN, Jens.

A Expedição do Planalto Central: notas para uma história espacial de Brasília. Terra Brasilis, Rio de Janeiro, n.6, p.43-76. 2004.

CRULS, Luiz.

Relatório Cruls: Relatório da Comissão

Exploradora do Planalto Central do Brasil. Brasília: Senado Federal. Edição fac-similar. 2003.

EDLER, Flávio Coelho. A constituição da medicina tropical no Brasil oitocentista: da climatologia à parasitologia médica. Tese (Doutorado) - Instituto de Medicina Social, Universidade Estadual do Rio de Janeiro, Rio de Janeiro. 1999.

FERREIRA, Luiz Otávio.

Uma interpretação higienista do Brasil Imperial. In: Heizer, Alda; Videira, Antonio Augusto Passos (Org). Ciência, civilização e impérios nos trópicos. Rio de Janeiro: Access. p.207-234. 2001.

LÉCUYER, Bernard P.

L'hygiene em France avant Pasteur: 1750-1850. In: Salomont-Bayet (Ed.). Pasteur et la révolution pastorienne. Paris: Payot. 1986.

LIMA, Nísia Trindade; HOCHMAN, Gilberto. Condenado pela raça, absolvido pela medicina: o Brasil descoberto pelo movimento sanitarista da Primeira República. In: Maio, Marcos Chor; Santos, Ricardo Ventura (Org). Raça, ciência e sociedade. Rio de Janeiro: Editora Fiocruz. p.23-40. 1996.
MIRANDA, Antonio Lisboa Carvalho de. Notícias bibliográficas sobre o dr. Antônio Martins de Azevedo Pimentel, precursor da historiografia brasiliense. In: Pimentel, Antônio Martins de Azevedo. A nova capital federal e o Planalto Central do Brasil. Brasília: Thesaurus. Edição fac-similar. 1985.

PIMENTEL, Antônio Martins de Azevedo. Anexo IV: Relatório do dr. Antonio Pimentel, medico hygienista da Commissão. In: Cruls, Luiz. Relatório Cruls: (relatório da Comissão Exploradora do Planalto Central do Brasil). Brasília: Senado Federal. p.237-272. 2003.

PIMENTEL, Antônio Martins de Azevedo. O Brasil central. Revista do Instituto Histórico e Geográfico Brasileiro, Rio de Janeiro, t.68, p.260-376. 1907.

PIMENTEL, Antônio Martins de Azevedo. Mudança da capital federal. Revista do Instituto Histórico e Geográfico Brasileiro, Rio de Janeiro, t.63, p.207-237. 1900.

RECLUS, Elisée

Nouvelle géographie universelle: la terre et les hommes. Paris: Librairie Hachette. 1894.

VERGARA, Moema de Rezende.

Ciência e história no relatório da Comissão Exploradora do Planalto Central na Primeira República. História, Ciência e Saúde Manguinhos, Rio de Janeiro, v.13, n.4, p.909-925. out.-dez. 2006. 